\title{
Article \\ A Truncated TIR-NBS Protein TN10 Pairs with Two Clustered TIR-NBS-LRR Immune Receptors and Contributes to Plant Immunity in Arabidopsis
}

\author{
Yongming Chen ${ }^{1}$, Guitao Zhong ${ }^{1,2}$, Huiren Cai ${ }^{1,2}$, Renjie Chen ${ }^{1}$, Na Liu ${ }^{1}$, Wei Wang ${ }^{1, *(1)}$ \\ and Dingzhong Tang $1, * \mathbb{B}$ \\ 1 State Key Laboratory of Ecological Control of Fujian-Taiwan Crop Pests, Key Laboratory of Ministry of \\ Education for Genetics, Breeding and Multiple Utilization of Crops, Plant Immunity Center, \\ Fujian Agriculture and Forestry University, Fuzhou 350002, China; Chesy6666@163.com (Y.C.); \\ guitaozhong@163.com (G.Z.); caihuiren@163.com (H.C.); ch_rjars@yeah.net (R.C.); \\ liuna20002004@163.com (N.L.) \\ 2 College of Life Science, Fujian Agriculture and Forestry University, Fuzhou 350002, China \\ * Correspondence: wangwei@fafu.edu.cn (W.W.); dztang@genetics.ac.cn (D.T.)
}

check for updates

Citation: Chen, Y.; Zhong, G.; Cai, H.; Chen, R.; Liu, N.; Wang, W.; Tang, D. A Truncated TIR-NBS Protein TN10 Pairs with Two Clustered TIR-NBS-LRR Immune Receptors and Contributes to Plant Immunity in Arabidopsis. Int. J. Mol. Sci. 2021, 22, 4004. https://doi.org/ $10.3390 /$ ijms22084004

Academic Editor: Marcello Iriti

Received: 12 March 2021

Accepted: 10 April 2021

Published: 13 April 2021

Publisher's Note: MDPI stays neutral with regard to jurisdictional claims in published maps and institutional affiliations.

Copyright: (c) 2021 by the authors. Licensee MDPI, Basel, Switzerland. This article is an open access article distributed under the terms and conditions of the Creative Commons Attribution (CC BY) license (https:/ / creativecommons.org/licenses/by/ $4.0 /)$.

\begin{abstract}
The encoding genes of plant intracellular nucleotide-binding site (NBS) and leucine-rich repeat (LRR) domain receptors (NLRs) often exist in the form of a gene cluster. Several recent studies demonstrated that the truncated Toll/interleukin-1 receptor-NBS (TIR-NBS) proteins play important roles in immunity. In this study, we identified a large TN gene cluster on Arabidopsis ecotype Col-0 chromosome 1, which included nine TN genes, TN4 to TN12. Interestingly, this cluster also contained two typical TIR-NBS-LRR genes: At1g72840 and At1g72860 (hereinafter referred to as TNL40 and TNL60, respectively), which formed head-to-head genomic arrangement with TN4 to TN12. However, the functions of these $T N$ and TNL genes in this cluster are still unknown. Here, we showed that the TIR domains of both TNL40 and TNL60 associated with TN10 specifically. Furthermore, both TNL40TIR and TNL60TIR induced cell death in Nicotiana tabacum leaves. Subcellular localization showed that TNL40 mainly localized in the cytoplasm, whereas TNL60 and TN10 localized in both the cytoplasm and nucleus. Additionally, the expression of TNL40, TNL60, and TN10 were co-regulated after inoculated with bacterial pathogens. Taken together, our study indicates that the truncated TIR-NBS protein TN10 associates with two clustered TNL immune receptors, and may work together in plant disease resistance
\end{abstract}

Keywords: plant immunity; NLRs; TIR; TN; TNL; cell death; ETI

\section{Introduction}

The growth environment of plants also contains a range of microorganisms, including viruses, bacteria, fungi, and oomycetes, some of which infect plants to exploit nutrition [1] In addition to non-host resistance, including natural physical barriers and constitutive synthesis of various enzymes and some secondary metabolites, plants also rely on the innate immune system to defend against pathogens [2-5]. The innate immune system of plants is mainly divided into two layers. Pattern recognition receptors (PRRs) at the plasma membrane recognize the conserved components of pathogens, pathogen-associated molecular patterns (PAMPs), or microbe-associated molecular patterns (MAMPs), and activate the first layer of immune responses, termed pattern-triggered immunity (PTI) $[2,6,7]$. The plant PRRs can be classified into two types: receptor-like kinases (RLKs) and receptor-like proteins (RLPs) based on the presence or absence of a kinase domain, respectively $[7,8]$. The well-studied RLKs in Arabidopsis include FLAGELLIN SENSING 2 (FLS2) and EF-TU RECEPTOR (EFR), which recognize conserved 22-amino acids peptide of bacterial flagellin (flg22) and the bacterial elongation factor TU (EF-TU), respectively [9-14]. 
Some host-adapted pathogens can secrete effectors that contribute to pathogen virulence into plant cells to interfere with plant immunity. Plants have evolved corresponding intracellular nucleotide-binding site (NBS) and leucine-rich repeat (LRR) domain receptors (NLRs), which are also called resistance (R) proteins that specifically recognize some effectors directly or indirectly and activate the second layer of immune responses, termed effector-triggered immunity (ETI) $[2,15,16]$. Compared with PTI, the response of ETI is often more intense and rapid, usually followed by hypersensitive responses (HR), a type of programmed cell death at the infection site $[17,18]$.

In plants, the typical NLR protein often contains a specific N-terminal domain, a conserved NBS domain, and a highly variable LRR domain at the C-terminus $[19,20]$. The specific $\mathrm{N}$-terminal domain is typically a coiled-coil (CC) domain, a Toll/interleukin receptor (TIR) domain or a RESISTANCE TO POWDERY MILDEW 8 (RPW8)-like domain. According to the difference of their N-terminal domain, NLRs are mainly divided into three subfamilies: CC-NBS-LRR (CNL), TIR-NBS-LRR (TNL), and RPW8-NBS-LRR (RNL) $[15,18,21]$. In addition to the typical NLRs containing all three characteristic domains, there are also some truncated NLRs [22,23]. For example, 21 truncated TIR-NBS (TN) proteins lacking C-terminal LRR domains are identified in Arabidopsis ecotype Col-0 [18,21-23]. Several recent studies demonstrated that TNs play an important role in plant immunity as well. For instance, the loss of function of TN8 and TN11 genes leads to enhanced susceptibility to Pseudomonas syringae pv. tomato (Pto) strain DC3000 [24]. Ectopic expression of the TIR domain of TN2 triggers cell death in tobacco. The autoimmune responses in exo70B1 mutants are caused by the activation of TN2 and co-expression EXO70B1 with TN2 can suppress the TN2-induced cell death in tobacco, indicating that TN2 may monitor EXO70B1 integrity $[25,26]$. Moreover, TN2 interacts with CALCIUM-DEPENDENT PROTEIN KINASE 5 (CPK5) and stabilizes the kinase activity of CPK5 [27]. TN13 is reported to be required for resistance against Pto DC3000 lacking the effectors AvrPto or AvrptoB [28]. The gain-of-function mutant of TN1, also known as CHILLING SENSITIVE 1 (CHS1), displays chilling sensitivity at low temperatures, and the chilling sensitive phenotypes of chs1-2 mutants at low temperatures are dependent on the full-length TNL protein SUPPRESSOR OF chs1-2, 3 (SOC3) [29-31]. SOC3 is found to associate with TN1 and TN2, respectively, to monitor the homeostasis of Arabidopsis E3 ubiquitin ligase SENESCENCE-ASSOCIATED E3 UBIQUITIN LIGASE1 (SAUL1). The over-accumulation of SAUL1 is monitored by the SOC3-TN2 pair, while SAUL1 disappearance is guarded by the SOC3-CHS1 pair [32,33].

Interestingly, SOC3 and CHS1/TN2 show a head-to-head orientation arrangement on the gene cluster $[31,33]$. The head-to-head clusters are frequently found for the plant NLR genes. For instance, RPS4-RRS1 from Arabidopsis is one of the best characterized head-to-head NLR pairs. RPS4 interacts with RRS1 through their TIR domains [34]. The WRKY domain of RRS1 was shown to be able to recognize different effectors to activate ETI responses. The ability of RPS4-RRS1 to activate the defense responses depends on both proteins being present and functional [35]. CHS3 and CSA1 is another head-to-head NLR pair in Arabidopsis [36]. Autoimmunity in the chs3-2D mutants requires the presence of a functional CSA1 protein [37], suggesting a cooperative activation mechanism requiring both CSA1 and CHS3. In rice, the head-to-head NLR pairs are also identified, such as RGA4RGA5 pair [38] and Pik-1-Pik-2 pair [39], indicating that the head-to-head arrangement of NLRs appears to be a conserved mechanism across species. The possible reason for this arrangement is that the paired NLRs are beneficial in co-regulation and co-evolution. Therefore, the investigation of the interaction between NLRs in gene clusters may reveal the functional link of unobserved NLR protein pairs [40].

In this study, through an analysis of the Arabidopsis ecotype Col-0 genome sequences, we found a large $T N$-type gene cluster on chromosome 1 . This cluster contains nine $T N$ genes named TN4, TN5, TN6, TN7, TN8, TN9, TN10, TN11, and TN12. Interestingly, two full-length $T N L$ genes, TNL40 and TNL60, were located at this gene cluster. Here, we show that TN10 interacted with TNL40 and TNL60. Transient expression of both TIR domains of TNL40 and TNL60 triggered cell death in N. tabacum. TNL40 localized in the cytoplasm, 
while TN10 and TNL60 localized in both the cytoplasm and nucleus. The co-expression of TNL40, TNL60, and TN10 was observed after the treatment of Pto DC3000 and Pto DC3000 avrRpt2. Our study suggested that TN10 may contribute to plant immunity by associating with both TNL40 and TNL60.

\section{Results}

\subsection{The TN4-TN12 Gene Cluster Contains Two Typical TNL Genes: TNL40 and TNL60}

The genome of Arabidopsis ecotype Col-0 contains 21 TN genes that are encoded by 20 genes and 1 pseudogene [23]. We found that the largest TN cluster was located on chromosome 1. As shown in Figure 1, this gene cluster contained nine TN genes, TN4$T N 12$, and all of these $T N$ genes were arranged in the same direction. It was reported that TN10 and TN11 shared the highest homology with TN8 and TN9, respectively [23]. Among these TN genes, the transcripts of TN7 and TN10 were reported to be higher than those of other TNs [22]. Interestingly, we observed that there were two full-length $T N L$ genes, TNL40 and TNL60, in this TN gene cluster (Figure 1), suggesting that the function of TN4-TN12 genes in plant immunity may be related to TNL40 and TNL60. Furthermore, TNL40 and TNL60 formed a head-to-head genomic arrangement with TN4-TN12 (Figure 1), which was reminiscent of the head-to-head arrangement of TNL gene SOC3 and TN genes TN1 and TN2 in the genome [31]. As both the TN1 and TN2 paired with SOC3 to monitor the homeostasis of SAUL1 [32,33], we hypothesized that TNL40 and TNL60 may also employ these $\mathrm{TN}$ proteins to monitor different substrates and activate downstream immune responses.

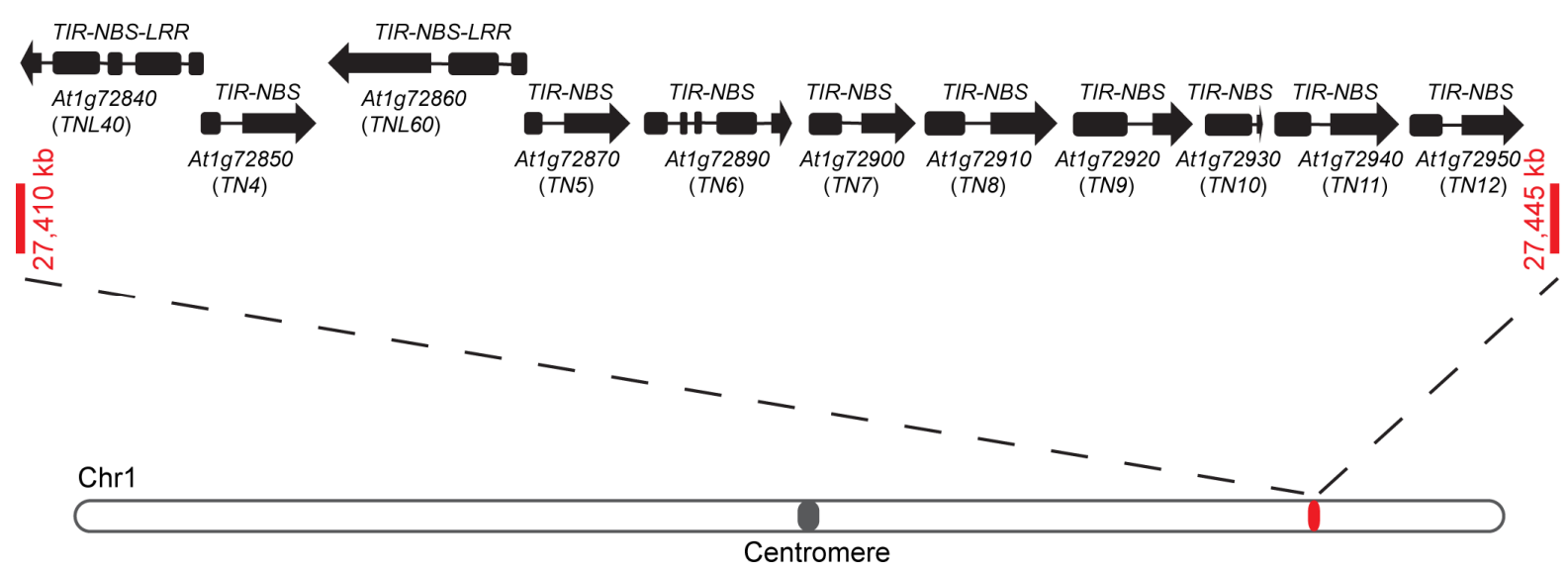

Figure 1. Schematic description of the largest Toll/interleukin receptor (TIR)-nucleotide binding site (NBS)-type (TN) gene cluster with two typical TIR-NBS-leucine-rich-repeat (TNL) genes, TNL40 and TNL60.

Exons and introns are represented by black boxes and solid lines, respectively. Arrows indicate the orientation of genes. The long bar at the bottom represents Arabidopsis chromosome 1. The gray dot represents the position of the centromere and the red dot represents the location of the indicated $T N$ gene cluster. The red bars and numbers represent the boundaries of these $T N$ gene cluster.

\subsection{TN10 Interacts with TNL40 and TNL60}

To investigate the functional link between these TNs and two TNL proteins, we first tested their interaction by performing firefly split-luciferase complementation (LUC) assays. As the activation and over-accumulation of TNL proteins may be toxic to plants, we generated a series of truncations of TNL40 and TNL60 based on their protein domains, including TNL40TIR, TNL40NBS, TNL40LRR, TNL60TIR, TNL60NBS, and TNL60LRR, respectively. In this LUC assay, the MYC-tagged N terminus of firefly luciferase (Nluc) was fused to the truncations of TNL40 and TNL60. Moreover, the C terminus (Cluc) was fused to each TN, except TN6 whose full-length coding sequence (CDS) was not cloned from 
Arabidopsis leaves, respectively. Different pairs of constructs were transiently expressed in 4-week-old N. benthamiana leaves and the luminescence signals were observed two days post inoculation (dpi). As shown in Supplementary Figure S1, we observed strong luminescence signals in both leaves co-expressing TN10 with TNL40TIR or TNL60TIR. We also confirmed the correct expression of these fusion proteins in the $N$. benthamiana leaves (Supplementary Figure S2), suggesting that TN10 may be the unique TN protein in this cluster that associated with both TNL40 and TNL60.

The TIR domain of the TNL protein is an intracellular signaling domain that triggers immunity, and the homo- or hetero-dimerization of TIR domains is crucial for immune signaling transduction $[17,18,34]$. To further confirm the interaction between TNs and TNL40 or TNL60, we next fused the TIR domain of each TN protein to Cluc and performed LUC assays with TNL40TIR-Nluc and TNL60TIR-Nluc, respectively. As shown in Supplementary Figure S3, we only observed strong luminescence signals in leaves coexpressing TNL40TIR-Nluc or TNL60TIR-Nluc with TN10TIR-Cluc, but not with other TNs Cluc-tagged TIR proteins, indicating that TNL40 and TNL60 mainly interacts with TN10. Therefore, we focused on TN10 mainly in the further investigation.

To confirm the interaction between TN10 and TNL40TIR or TNL60TIR, we next performed the LUC assay with appropriate controls. In this assay, we fused yellow fluorescence protein (YFP) to Cluc and Nluc, respectively, to act as negative controls. After co-expression of different pairs in N. benthamiana leaves, we found that TN10-Cluc associated with both TNL40TIR-Nluc and TNL60TIR-Nluc, but not with YFP-Nluc, and there is no interaction between YFP-Cluc and TNL40TIR-Nluc or TNL60TIR-Nluc (Figure 2A). We also confirmed the correct expression of all these fusion proteins (Supplementary Figure S4). These data indicate that TN10-Cluc associates with TNL40TIR-NLuc and TNL60TIR-Nluc specifically.

To further confirm this result, we next performed a co-immunoprecipitation (Co-IP) assay in which we transiently expressed GFP, TNL40TIR-GFP, or TNL60TIR-GFP with TN10-MYC in 4-week-old Arabidopsis protoplasts (Figure 2B). When we immunoprecipitated GFP, TNL40TIR-GFP, and TNL60TIR-GFP proteins using an anti-GFP antibody, TN10-MYC protein was detected with an anti-MYC antibody only in the precipitate from the leaves that co-expressed both TN10-MYC and TNL40TIR-GFP or TNL60TIR-GFP, but not from the negative control leaves that expressed TN10-MYC and GFP (Figure 2B), indicating again that TN10 can form a complex with TNL40TIR or TNL60TIR in Arabidopsis.

\subsection{TN10 Contains A Typical TIR Domain}

To gain more insights into the TN10 protein, we performed the alignments of protein amino acid sequences with the well-characterized TNL protein L6 and RESISTANCE TO PSEUDOMONAS SYRINGAE 4 (RPS4), as well as TN2. We found that all TN10, TNL40, and TNL60 contained a typical TIR domain (Supplementary Figure S5), including four conserved TIR subdomains (TIR1-TIR4) [30,36]. Several recent studies demonstrated that the TIR domains of TNL proteins were able to cleave nicotinamide adenine dinucleotide in its oxidized form $\left(\mathrm{NAD}^{+}\right)$and transmit signals downstream to trigger cell death [41-43]. Furthermore, a conserved glutamic acid (Glu, E) was found to be required for the activity of plant TIR domain to act as a NAD ${ }^{+}$-cleaving enzyme (NADase) [41]. As shown in Supplementary Figure S5, we also found that the conserved Glu was present in the TIR2 subdomain of all aligned TIR-type proteins, indicating again that TN10, TNL40, and TNL60 carry typical TIR domains. 
A
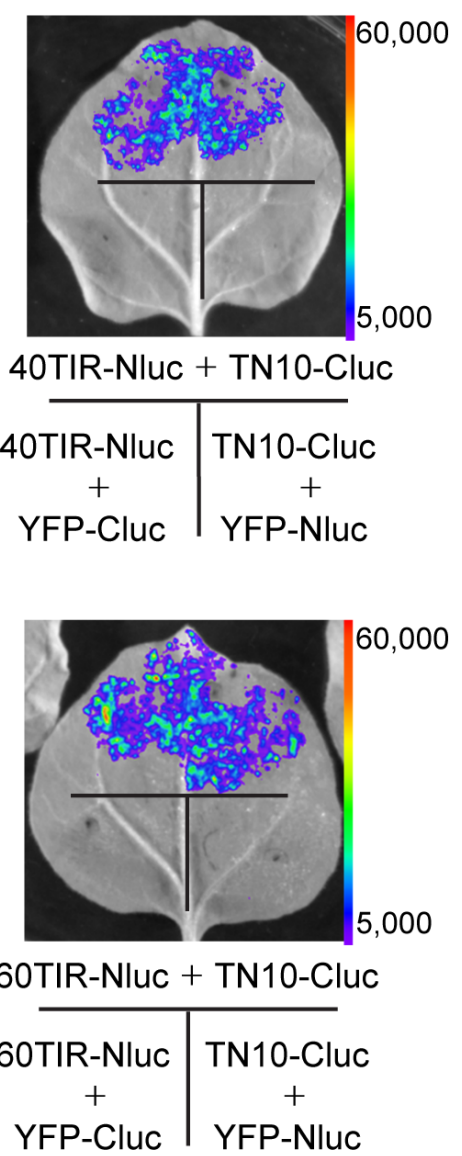

B

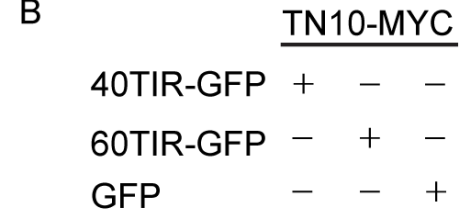

IP: anti-GFP
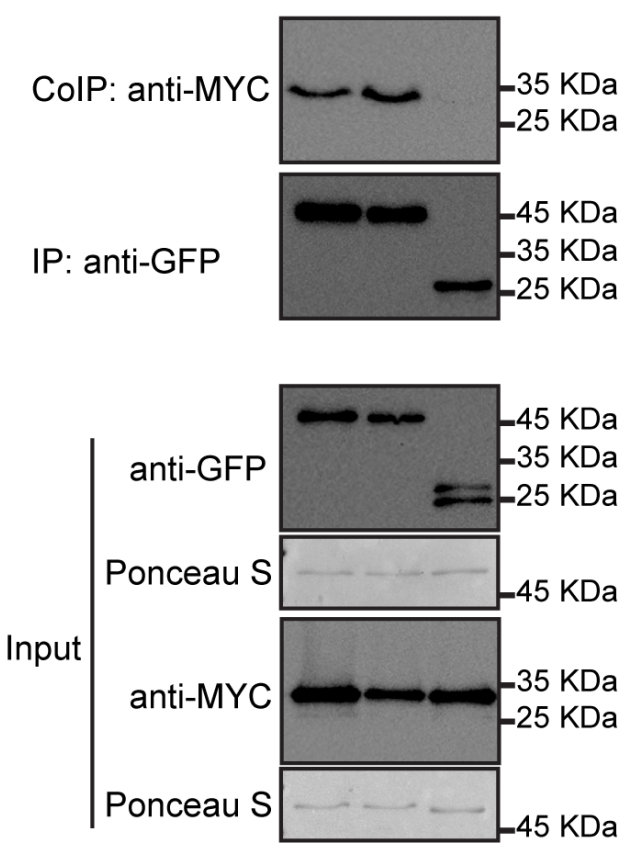

Figure 2. The Toll/interleukin-1 receptor (TIR) domains of TNL40 and TNL60 interact with TN10 in planta. (A) Images of N. benthamiana leaves two days after inoculation with indicated constructs in a firefly split-luciferase complementation imaging (LUC) assay. The coding sequence (CDS) of TN10 was fused to the C-terminal fragment to firefly luciferase $(\mathrm{Cluc})$ and the CDS of TNL40TIR or TNL60TIR was fused to the N-terminal fragment to firefly luciferase $(N l u c)$. The indicated constructs were transiently co-expressed in 4-week-old N. benthamiana leaves. Yellow fluorescence protein (YFP)Cluc and YFP-Nluc were used as the negative controls. (B) The interaction analysis of TNL40TIR-GFP or TNL60TIR-GFP with TN10-MYC in a co-immunoprecipitation (Co-IP) assay $16 \mathrm{~h}$ after transfection of Arabidopsis Col-0 protoplasts. The expression of GFP with TN10-MYC was used as a negative control. Proteins were detected by immunoblotting using anti-GFP and anti-MYC antibodies.

Moreover, we found that the motifs defining the NBS, ARC1 (Apaf-1, R proteins, CED-4, 1), and ARC2 subdomains were conserved in TNL40, TNL60, L6, and RPS4 (Supplementary Figure S5) [44]. As typical TNL proteins, TNL40 and TNL60 also contained GKT-type Walker A/P-loop motifs, a conserved GNNNNGKT sequence ( $\mathrm{N}$ represents any amino acid residue) that is essential for the binding of ATP $[45,46]$ in their NBS domain, while it is a GRS-type P-loop motif (GNNNNGRS) in TN2 (Supplementary Figure S5). In addition, the conserved MHD (methionine-histidine-aspartate) motif required for function/activity of TNL was also observed in the NBS domains of TNL40 and TNL60 [44,47], but not in the NBS domains of TN2 and TN10 (Supplementary Figure S5), indicating again that TNL40 and TNL60 are typical TNL proteins. Different from other TN proteins, we found that TN10 not only lacks LRR domains, but also misses most of the NBS domain sequences, including the P-loop motif in its NBS domain (Supplementary Figure S5), suggesting that the function of TN10 in plant immunity may be different from other $\mathrm{TN}$ proteins. 


\subsection{Subcellular Localization of TNL40, TNL60, and TN10}

In order to explore the function of TNL40, TNL60, and TN10, we next examined TNL40-GFP, TNL60-GFP, and TN10-GFP subcellular localization in N. benthamiana leaves. The expression of GFP alone was used as a negative control. Consistent with the previous report [22], we observed that TN10-GFP localized in both the cytoplasm and nucleus (Figure 3). Interestingly, TNL40 mainly localized in the cytoplasm (Figure 3 and Supplementary Figure S6), while TNL60 localized in the cytoplasm and nucleus (Figure 3). All proteins of the correct size without free GFP were detected by an immunoblotting analysis with an anti-GFP antibody (Supplementary Figure S7).

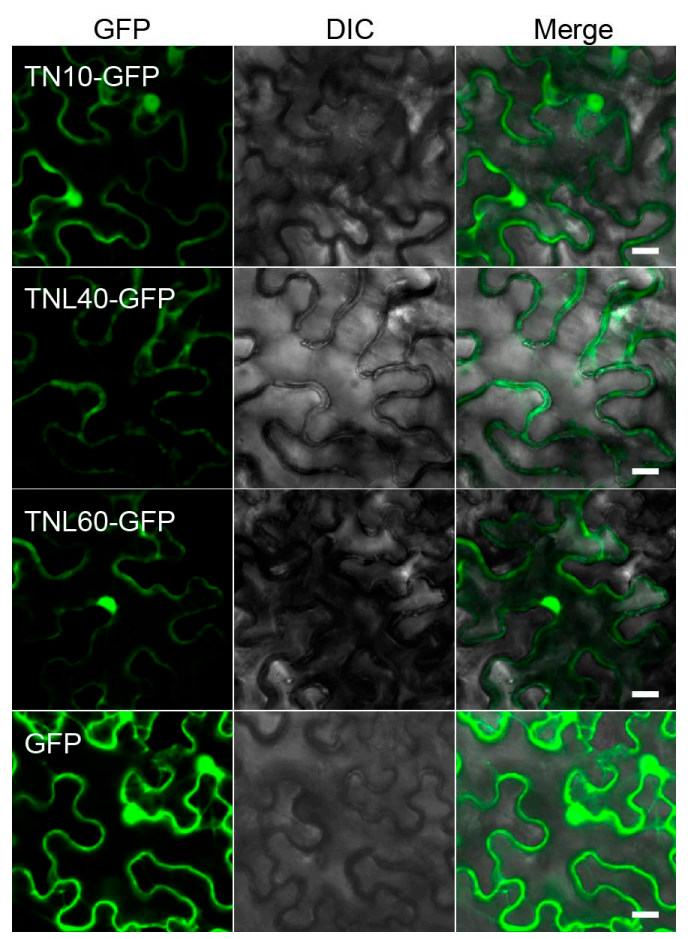

Figure 3. Subcellular localizations of TN10, TNL40, and TNL60. Subcellular localization of TN10, TNL40, and TNL60 in N. benthamiana leaves. The TN10-GFP, TNL40-GFP, and TNL60-GFP were transiently expressed in 4-week-old N.benthamiana leaves. GFP fluorescence was visualized $48 \mathrm{~h}$ after transformation. The GFP alone protein was used as a control. Bar $=20 \mu \mathrm{m}$.

\subsection{Overexpression of TNL40TIR and TNL60TIR Induced Cell Death in N. tabacum}

Overexpression of TNL proteins or their TIR domains in N. tabacum leaves often leads to cell death $[18,41]$. However, whether these TN proteins can trigger cell death is unclear. Then, with TN2 as a positive control, we transiently expressed TN4, TN5, TN7, TN8, TN9, TN10, TN11, and TN12 protein in N. tabacum leaves. Four days after injection, we observed that the expression of TN2 induced significant cell death, which is consistent with a previous report [26]. Similarly, we found that TN11 and TN12, but not other TNs in this cluster, can also trigger obvious cell death (Figure 4A), and the TN4, TN5, TN7, TN8, TN9, and TN10 proteins were accumulated at the correct size (Figure 4B). In addition, we also observed that the expression of the TIR domains, but not the NBS or LRR domains, of TNL40 and TNL60 can trigger cell death in N. tabacum leaves (Figure 4C,D).

Interestingly, we found that the cell death triggered by TNL40TIR was weaker than that by TNL60TIR. To further test this, we next expressed TNL40TIR-GFP, TNL60TIR-GFP, and TN10-GFP in N. tabacum leaves and observed the occurrence of cell death. As shown in Figure 5A, we found that the TNL60TIR triggered cell death was obvious 3 days after injection, while the TNL40TIR induced cell death was still not very obvious, indicating that the hypersensitive response activated by TNL40 was weaker than TNL60 (Figure 5A). Additionally, we also tested the accumulation of protein levels of TNL40TIR, TNL60TIR, 
and TN10, and found all proteins were expressed and accumulated (Figure 5B), indicating again that TNL40 and TNL60 carry typical and functional TIR domains.
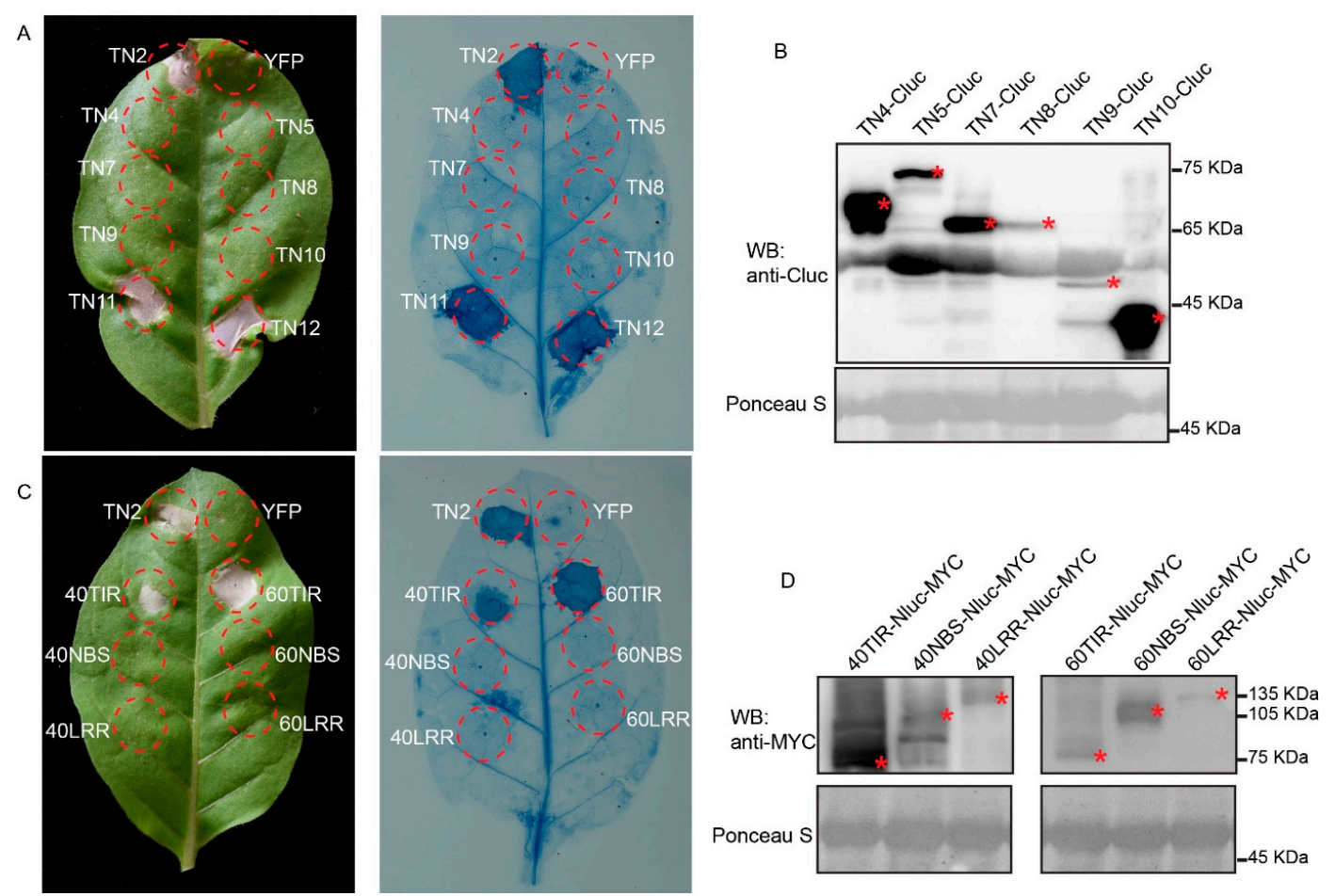

Figure 4. Overexpression of Arabidopsis TN4-TN12 and TNL40/60 canonical domain in N. tabacum leaves. (A) Transient overexpression of TN4-Cluc, TN5-Cluc, TN7-Cluc, TN8-Cluc, TN9-Cluc, TN10-Cluc, TN11-Cluc, and TN12-Cluc in N. tabacum leaves and cell death was observed and photographed at 4 days after injection. TN2 was used as a positive control and YFP-Cluc was used as a negative control. (B) Immunoblotting analysis of the accumulation of TN4-Cluc, TN5-Cluc, TN7Cluc, TN8-Cluc, TN9-Cluc, TN10-Cluc proteins in N. tabacum leaves. Asterisks indicate the position of the corresponding proteins. (C) Transient overexpression of 40TIR-Nluc-MYC, 40NBS-Nluc-MYC, 40LRR-Nluc-MYC, 60TIR-Nluc-MYC, 60NBS-Nluc-MYC, 60LRR-Nluc-MYC in N. tabacum leaves and cell death was observed and photographed at 4 days after injection. TN2 was used as a positive control and YFP-Nluc was used as a negative control. (D) Immunoblotting analysis of the accumulation of 40TIR-Nluc-MYC, 40NBS-Nluc-MYC, 40LRR-Nluc-MYC, 60TIR-Nluc-MYC, 60NBS-Nluc-MYC, 60LRR-Nluc-MYC proteins in N. tabacum leaves. Asterisks $\left(^{*}\right)$ indicate the position of the corresponding proteins.
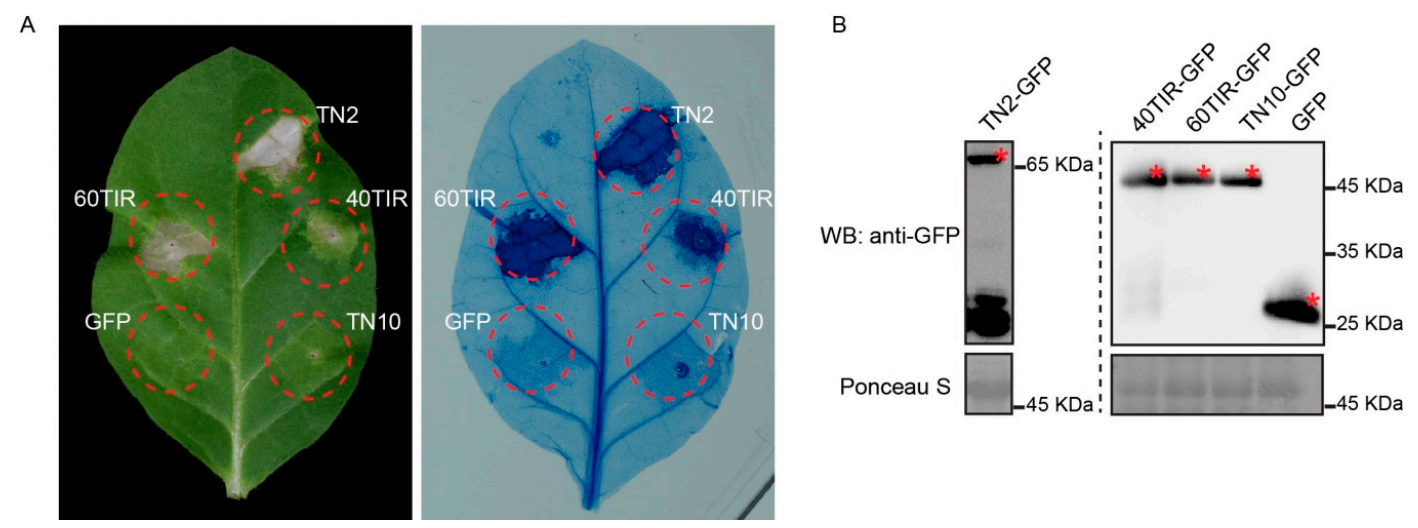

Figure 5. Transient overexpression of TNL40TIR and TNL60TIR in tobacco results in cell death. (A) Transient overexpression of TNL40TIR, TNL60TIR, and TN10 in N. tabacum leaves and the cell death were observed and photographed at 3 days after injection. TN2-GFP was used as a positive control and GFP was used as a negative control. (B) Immunoblotting analysis of the accumulation of TN2-GFP, TNL40TIR-GFP, TNL60TIR-GFP, TN10-GFP, and GFP proteins in N. tabacum leaves before cell death occurred. Asterisks indicate the position of the corresponding proteins. 


\subsection{Expression of TNL40, TNL60, and TN10 after Infected with Bacterial Pathogens}

The pattern of expression of TNL40, TNL60, and TN10 under inoculation with patho gens may provide some clues to their cellular roles. In order to explore the role and functional link of TNL40, TNL60, and TN10 in disease resistance, we next inoculated the 4-week-old Arabidopsis wild-type Col-0 leaves with Pto DC3000, Pto DC3000 avrRpt2, and Pto DC3000 avrRps4, respectively, and analyzed the mRNA expression levels of TNL40, TNL60, and TN10 by quantitative reverse transcription (qRT)-PCR. The initial transcription level of TN10 was very high (Figure 6), which is consistent with the previous reports [22,23]. We found that both TNL genes, TNL40 and TNL60, were up-regulated after being infected with Pto DC3000, Pto DC3000 avrRpt2, and Pto DC3000 avrRps4 (Figure 6), suggesting that TNL40 and TNL60 may play a role after pathogens invasion. Interestingly, we found that the transcripts of TN10 increased significantly six hours after treatment with Pto DC3000 and Pto DC3000 avrRpt2, but decreased significantly six hours after treatment with Pto DC3000 avrRps4 (Figure 6), indicating that TN10 plays different roles in the resistance response mediated by different effectors. However, different to the inoculation with Pto DC3000 avrRpt2, we observed that the up-regulated expression of TN10 was dropped to initial level $12 \mathrm{~h}$ after inoculation with Pto DC3000 (Figure 6A,B), suggesting that TN10 may only play a role in the resistance to Pto DC3000 at the early time of infection.

A
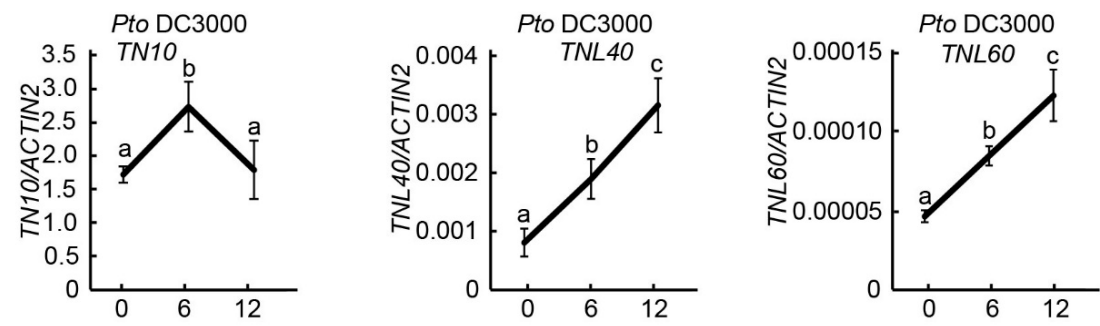

B
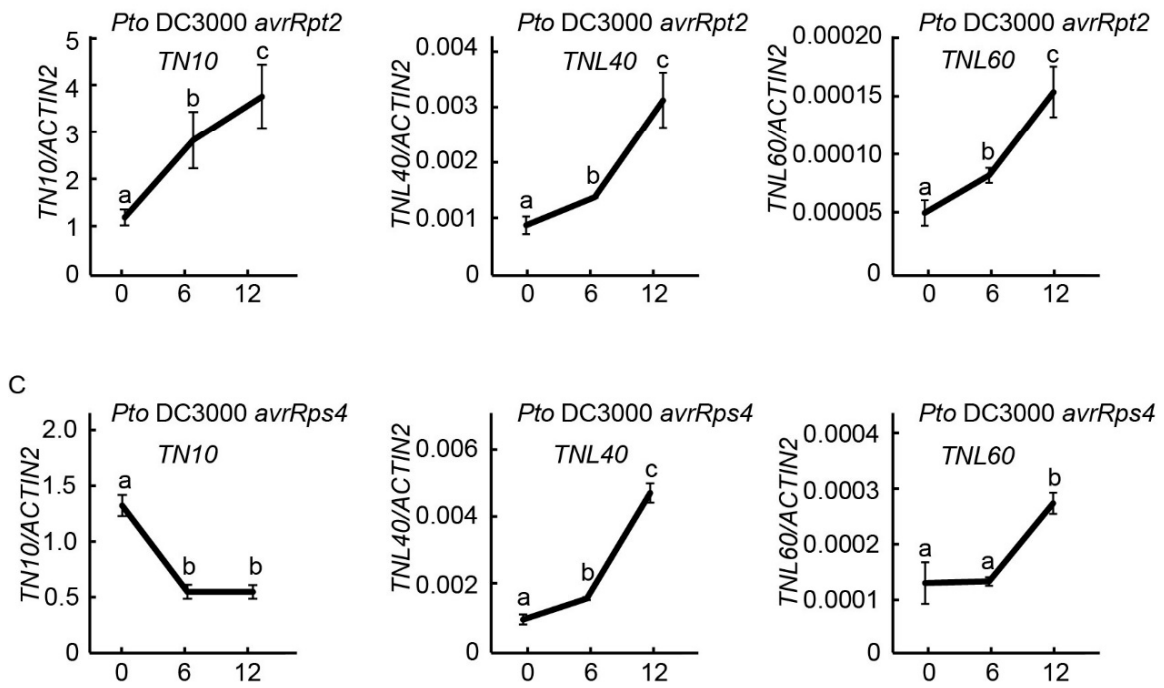

Figure 6. Expression of TN10, TNL40, and TNL60 genes in Arabidopsis Col-0 plants after infiltration with different Pto DC3000 strains. The expression levels of TN10, TNL40, and TNL60 genes were measured using qRT-PCR after inoculation with Pto DC3000 (A), Pto DC3000 avrRpt2 (B), and Pto DC3000 avrRps4 (C). The y-axis represents the relative expression level that was normalized to those of ACTIN2, and the x-axis represents the indicated time point (hours) after inoculation. Lower-case letters indicated statistically significant differences $(p<0.05$, ANOVA, $n=3)$. 


\section{Discussion}

The head-to-head arranged NLR gene pairs have been reported in many studies [33,38,40,48-52]. In this article, we found that there was a large TN-TNL gene cluster on Arabidopsis chromosome 1 and showed the association of TN10 with TNL40TIR and TNL60TIR. As far as we know, this is the first report that an atypical TN protein was shown to interact with the TIR domain of two full-length TNL proteins. Furthermore, we tested the subcellular localization of TNL40, TNL60, and TN10, and showed that TNL40 mainly localized in the cytoplasm, while TN10 and TNL60 localized in both the cytoplasm and nucleus. In addition, the observation of co-regulation of transcripts of TN10 with TNL40 and TNL60 further indicated that TN10 may form complexes with TNL40 and TNL60 to regulate plant immunity.

The head-to-head genomic arrangements play important roles in regulating the cooperation of NLR proteins as almost all of the identified paired NLRs are encoded by physically linked genes [40]. For example, the SOC3-CHS1 pair and SOC3-TN2 pair are the two firstly identified unique NLR pairs formed by a full-length TNL and a truncated TN protein [33,49]. The over-accumulation and disappearance of Arabidopsis E3 ligase SAUL1 are monitored by SOC3-TN2 and SOC3-TN1, respectively [32,33]. SOC3, CHS1, and TN2 genes also show head-to-head genomic arrangement on chromosome $1[31,33,49]$. These reports suggested that the analysis of the interaction of NLR proteins in gene clusters may reveal new NLR protein pairs [35,38-40,51]. We next analyzed the Arabidopsis genome and found that the largest $T N s$ gene cluster was located on chromosome 1 . Two typical $T N L$ genes were found in this cluster, suggesting that they may function together in plant immunity. Interestingly, in our further investigation, we found that only TN10 in this cluster interacted strongly with both TIR domains of TNL40 and TNL60, indicating that TN10 may transmit signals to TNL40 and TNL60 to regulate plant immunity. Why other TNs in this cluster did not obviously interact with TNL40 or TNL60 and what targets were guarded by TNL40-TN10 and TNL60-TN10 pairs needs to be further investigated.

In plants, the TIR domain of TNL plays a crucial role in immune signaling since ectopic expression of certain TIR domain triggers strong cell death in tobacco [31,53]. Recent studies showed that, similar to the TIR domain of animals, the plant TIR domain also has NADase activity, which is required for cell death induction [41,42]. As shown in Supplementary Figure S5, we found that both the TIR domains of TNL40 and TNL60 contained the conserved glutamic acid, which is necessary for their potential NADase activity, in the putative catalytic residue. Consistent with this, both TNL40TIR and TNL60TIR could trigger cell death in $N$. tabacum leaves. Interestingly, although the alignments of protein sequences showed that TN10 contained the typical TIR domain and the conserved glutamic acid in its putative catalytic residue, we did not observe obvious cell death in N. tabacum leaves expressing TN10 in our experimental conditions. However, the TN10 protein was accumulated in N. tabacum leaves. Moreover, it is noteworthy that we found very high transcripts of TN10 in the untreated plants, which is consistent with a previous report $[22,23]$. Together with the fact that TN10 protein misses most of the NBS domain sequences, including P-loop and MHD motifs, we proposed that TN10 may mainly function in transmitting immune signals. Furthermore, it is worth noting that the well-characterized TIR-only functional immune receptor RESPONSE TO HOPBA 1 (RBA1), which is sufficient to trigger cell death in response to HopBA1, functions as a pathogen sensor [54]. It is possible that TN10, as a TIR-only receptor, may be functionally similar to RBA1 in effector recognition and immune activation.

Similar to the pentamerized resistosome formed by the CNL protein ZAR1 [19,55], two more recent studies showed that the TNL proteins RPP1 and ROQ1 can form the tetramerized resistosome required for their NADase activity [56,57]. The existence of TNL resistosome may serve as a platform to recruit TIR-only proteins or other oligomerized TNLs to form complexes and expand TNL-mediated immune signals [56]. Similarly, whether TNL40 and TNL60 can form tetramerized resistosome remains to be determined. It is possible that TN10 may also participate in the process of TNL tetramerization resistosome. 
The prominent TIR domain in the resistosome enhances its NADase enzyme activity, so it will be interesting to determine whether TN10 affects the prominent TIR domain in the TNL resistosome. In addition, whether TN10 can form a tetramerization by its TIR domain is also an interesting question to be determined.

The mRNA expression levels of TN10, TNL40, and TNL60 were co-regulated after inoculation with Pto DC3000 and Pto DC3000 avrRpt2, but not with Pto DC3000 avrRps4, suggesting that TN10 may function together with TNL40 and TNL60 in response to different effectors. Interestingly, we found that the up-regulation of TN10 transcripts significantly occurred six hours after injection with Pto DC3000 and Pto DC3000 avrRpt2, but the expression of TNL40 and TNL60 was obviously increased $12 \mathrm{~h}$ after injection with Pto DC3000 and Pto DC3000 avrRpt2, indicating that the up-regulation of TNL40 and TNL60 is later than TN10, and TN10 may sense the attack of bacteria and transmit the signals to TNL40 and TNL60 to activate immunity. The expression trend of TN10 after inoculation with Pto DC3000 is similar to the treatment of salicylic acid (SA) [22], indicating that TN10 plays a positive role in the early stage of immune responses, which is consistent with the previous report that the TN10 overexpression plants display enhanced resistance to Pto DC3000 [22]. However, it will also be interesting to investigate why the transcripts of TN10 are induced by Pto DC3000 avrRpt2 as the effector AvrRpt2 is recognized by the well-characterized CNL RPS2.

Arabidopsis ecotype Col-0 has only about 82 TNLs and 51 CNLs, which are sufficient to deal with the invasion and colonization of most external pathogens [23]. How plants use limited NLR proteins to resist the complex environment has become a key issue. Previous studies have suggested that the proteins encoded by the clustered NLRs may act together in activating immune responses and may be likely to provide coregulatory benefits [40]. Our results here showed that the atypical TN protein TN10 can interact with TNL40TIR and TNL60TIR. Based on these results, we proposed a possible working model for the functional mechanism of TN10, TNL40, and TNL60 in plant immunity (Figure 7). In the resting cell, TNL40 and TNL60 are kept in inactive states through the interaction between their domains. When pathogens such as bacteria secrete effectors into plant cells, TN10 interacts with the TIR domain of TNL40 or TNL60, leading to the change of the conformation of the full-length TNL proteins, thereby releasing the full-length TNL to activate ETI responses. Additionally, how TN10 activates and helps the full-length TNL proteins perform functions are also interesting questions that need to be determined in the further investigation.

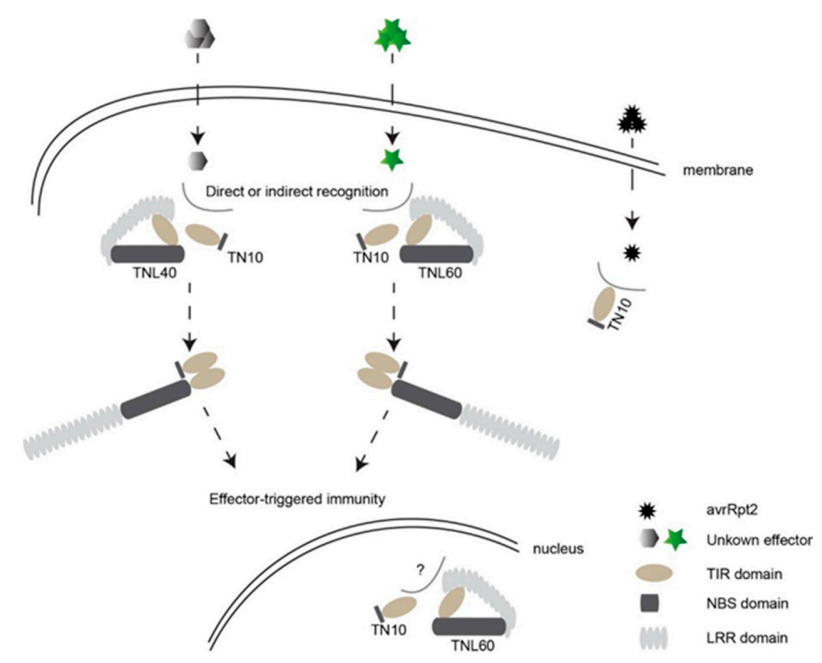

Figure 7. A possible model summarizing the function of TNL40, TNL60, and TN10 proteins in plant immunity. In the resting cell, TNL40 and TNL60 are kept in inactive states through the interaction between their domains. When plants were attacked by pathogens, TN10 interacted with TNL40 or TNL60 and resulted in the changes of the conformation of TNL proteins followed by the activation of effector-triggered immunity (ETI) responses. TNL40, TNL60, and TN10 may also function as accessory components in signal transduction during defense responses. 
In summary, our results here showed that TNL40, TNL60, and TN10 were located in the largest TN-TNL gene cluster in a head-to-head genomic arrangement. Transient expression of the TIR domains of TNL40 and TNL60 triggered cell death in N. tabacum leaves. Moreover, TN10 interacted with both TNL40TIR and TNL60TIR, and the observation of co-expression of TNL40, TNL60, and TN10 after infection with Pto DC3000 suggested that TN10 pairs with TNL40 and TNL60 may contribute to immune signaling.

\section{Materials and Methods}

\subsection{Plant Materials and Growth Conditions}

The wild-type Arabidopsis thaliana accession used in this study was Columbia-0 (Col-0), seeds were surface-sterilized by $70 \%$ ethanol and planted on plates containing a halfstrength Murashige and Skoog (1/2 MS) medium with 1\% sucrose. Plates were kept in $4{ }^{\circ} \mathrm{C}$ for 3 days and moved to the growth room, and then transplanted into soil (nutrient soil/vermiculite 2: 1) 7 days after germination. Arabidopsis thaliana plants were grown in a growth room at $22{ }^{\circ} \mathrm{C}$ with approximately $60 \%$ relative humidity and 9 -h-light/15-h-dark photoperiod, with a light intensity of 7000-8000 lux for protoplasts preparation and gene expression assay. Nicotiana benthamiana and Nicotiana tabacum plants were grown under the same growth conditions as Arabidopsis [58].

\subsection{Plasmid Constructs}

All CDS sequences containing TN4-TN12, TNL40, and TNL60 used in this research were derived from the Arabidopsis thaliana Col-0 accession. Plasmids used in this study were constructed by In-fusion technology's One-Step Cloning Kit (Vazyme, Nanjing, China. C112). All clones were verified with DNA sequencing. For the firefly split-luciferase complementation assay, the CDS of TN4, TN5, TN7, TN8, TN9, TN10, TN11, TN12, TN4TIR, TN5TIR, TN7TIR, TN8TIR, TN9TIR, TN11TIR, and TN12TIR were amplified with specific primers and then cloned into pCAMBIA1300-Cluc, respectively. The CDS of TNL40TIR, TNL40NBS, TNL40LRR, TNL60TIR, TNL60NBS, and TNL60LRR were amplified with specific primers and then cloned into pCAMBIA1300-Nluc-MYC, respectively. For the Co-IP assay, TNL40TIR and TNL60TIR was cloned into pSuper1300 with a GFP tag, TN10 was cloned into pSuper1300 with a $6 \times \mathrm{MYC}$ tag. For the subcellular localization assay, the fulllength TNL40, TNL60 and TN10 CDS sequences were amplified and then cloned into pSuper1300 with a GFP tag. The primers used for the plasmid constructs are listed in Supplementary Table S1.

\subsection{Cell Death Assay in N. tabacum Leaves and Tobacco Protein Extraction}

Agrobacterium strain GV3101 carrying the targeted plasmid was resuspended to $\mathrm{OD}_{600}=0.4 \mathrm{in}$ an injection buffer $(10 \mathrm{mM}$ MES [pH 5.6], $10 \mathrm{mM} \mathrm{MgCl}, 150 \mu \mathrm{M}$ Acetosyringone), then gently injected into the tobacco leaf using a 1-mL needle-free syringe. The tobacco was cultivated in the dark for $12 \mathrm{~h}$, then transferred to the short-day growth conditions. For cell death leaf observation experiments, the pictures were taken at 3 or 4 days after injection. Then, the indicated $N$. tabacum leaves were stained with trypan blue and decolorized overnight. For protein extraction experiments, the samples were taken $36 \mathrm{~h}$ after injection (before cell death occurrence). The leaves were frozen quickly in liquid nitrogen and ground into powders in a mortar. Then, the sample was transferred to a new 2-mL centrifuge tube. Native extraction buffer (50 mM Tris-MES [pH 8.0], 0.5 M Sucrose, $1 \mathrm{mM} \mathrm{MgCl}_{2}, 10 \mathrm{mM}$ EDTA, $5 \mathrm{mM}$ DTT, and 1\% [w/v] protease inhibitor cocktail S8830 [Sigma, St. Louis, MO, USA]) was added in a ratio of $1 \mathrm{~g}$ to $2 \mathrm{~mL}$. The tubes were placed on ice for $30 \mathrm{~min}$ and centrifuged at $12,000 \mathrm{~g}$ for $15 \mathrm{~min}$, and then the supernatant was transferred to a new centrifuge tube to be used in the next protein immunoblotting assay performed as described previously [59]. 


\subsection{Firefly Split-Luciferase Complementation Assay}

Pairs of Agrobacterium GV3101 strains containing the targeted plasmid combinations were resuspended in an injection buffer (the final concentration of each stain injection was OD $600=0.4$ ), and then co-transformed into 4-week-old N. benthamiana leaves and incubated in the short-day condition growth room for $48 \mathrm{~h}$. The $N$. benthamiana leaves were sprayed with $1 \mathrm{mM}$ precooled luciferin, and the samples were placed in darkness for $5 \mathrm{~min}$. Subsequently, LUC images were captured with a low-light cooled CCD imaging apparatus. The details of this assay were described previously [60].

\subsection{Transient Expression in Arabidopsis Protoplasts}

Protoplasts were prepared from 4-week-old Arabidopsis Col-0 leaves and transfections were done as described previously [61]. After transfection, protoplasts were incubated at room temperature under weak light for $16 \mathrm{~h}$, and protein extracts were prepared for immunoblotting and Co-IP assays.

\subsection{Protoplast Protein Extraction, Immunoprecipitation, and Immunoblotting}

Protoplast proteins were processed in extraction buffer $(50 \mathrm{mM}$ Tris [pH 7.5], $150 \mathrm{mM}$ $\mathrm{NaCl}, 10 \%(v / v)$ glycerol, $2 \mathrm{mM}$ EDTA, $5 \mathrm{mM}$ DTT, $1 \%$ [ $w / v]$ protease inhibitor cocktail S8830 [Sigma], 0.1\% Triton). Lysates were centrifuged for $15 \mathrm{~min}$ at $14,000 \mathrm{rpm}$ at $4{ }^{\circ} \mathrm{C}$. Aliquots of supernatants were used as input samples. For immunoprecipitation assays, $20 \mu \mathrm{L}$ GFP-Trap Magnetic Agarose (Chromotek, Munich, Germany) was added to $1 \mathrm{~mL}$ total protein extract for $2 \mathrm{~h}$ incubation at $4{ }^{\circ} \mathrm{C}$. Beads were collected by centrifugation and washed four times with a PBS buffer containing $0.1 \%(v / v)$ Triton X-100. Then, beads were resuspended in $80 \mu \mathrm{L}$ of PBS buffer with SDS loading buffer and incubated at $95{ }^{\circ} \mathrm{C}$ for $8 \mathrm{~min}$. Proteins were separated via SDS-PAGE gels and analyzed by immunoblotting. The anti-bodies used were anti-GFP (Sigma Aldrich, Louis, MO, USA, 11814460001) and anti-MYC (Sigma Aldrich, Louis, MO, USA, 11867423001).

\subsection{Subcellular Localization Assay}

The constructs were transformed into the Agrobacterium GV3101 strain and injected into N. benthamiana leaves. Plants were placed in the dark for $12 \mathrm{~h}$ and then transferred to the short-day growth conditions for $36 \mathrm{~h}$, then the leaves were taken for observation. Green fluorescent protein (GFP) fluorescence was visualized using a confocal laser scanning microscope (Zeiss 880 ) under a $\times 20$ objective, zoom $\times 0.8,2048 \times 2048$ pixels, and imaged TN10-GFP and TNL40/60-GFP with 2 and $10 \%$ of the $488-\mathrm{nm}$ line, respectively, and detected in the range $494-598 \mathrm{~nm}$.

\subsection{Pathogen Infection Assays and Gene Expression Analysis}

Pseudomonas syringae pv. tomato (Pto) DC3000 or Pto DC3000 AvrRpt2, Pto DC3000 AvrRps4 strains were cultured on the King' B medium containing appropriate antibiotics at $28^{\circ} \mathrm{C}$ for two days. The $10 \mathrm{mM} \mathrm{MgCl}{ }_{2}$ containing buffer was used to resuspend bacteria to $\mathrm{OD}_{600}=0.1$. Leaves from 4-week-old plants were infiltrated with suspensions of different Pto DC3000 strains. The samples were taken at 0,6 , and $12 \mathrm{~h}$ after inoculation and frozen in liquid nitrogen. Total RNA was extracted by the TRIzol reagent (Invitrogen, Carlsbad, CA, USA) according to the manufacturer's instructions, and the first strand was synthesized using a RT reagent kit (code number is RR047A; Takara, Dalian, China). Accumulation of transcripts was examined by qRT-PCR using the RT reagent Kit (code number is RR047A; Takara, Dalian, China). All qRT-PCR assays were performed with the Premix Ex Taq Kit (code number is RR420A; TaKaRa, Dalian, China) in a CFX Connect Real-time PCR System (BIO-RAD, Hercules, CA, USA). The ACTIN2 gene was used as an internal control. All of the primers used for qRT-PCR are listed in Supplementary Table S1. 


\section{Conclusions}

In this study, we identified the largest TN-TNL gene cluster in the Arabidopsis ecotype Col-0 genome. Two full-length TNL genes, TNL40 and TNL60, were arranged in a head-tohead orientation with TN4-TN12. TNL40 and TNL60 interacted strongly with TN10, which is almost a naked TIR domain. TNL40, TNL60, and TN10 localized in the cytoplasm, and TN10 and TNL60 also localized in the nucleus. The transcripts of TNL40, TNL60, and TN10 were co-induced when inoculated with Pto DC3000. Furthermore, both TNL40TIR and TNL60TIR induced cell death in N. tabacum leaves. Based on these data, we hypothesized that TNL40 and TNL60 were kept in inactive states in the resting cell. When bacterial pathogens attacked, TN10 interacted with TNL40 or TNL60 to change the conformation of the full-length TNLs, and then activated the ETI immune signaling.

Supplementary Materials: The Supplementary Materials are available online at https:/ /www.mdpi. com/article/10.3390/ijms22084004/s1.

Author Contributions: D.T. and W.W. conceived and designed the research. Y.C., G.Z., H.C. and R.C. carried out most experiments. Y.C., N.L., W.W. and D.T. analyzed the data. Y.C., W.W. and D.T. wrote the manuscript. All authors have read and agreed to the published version of the manuscript.

Funding: The work was supported by grants from the National Natural Science Foundation of China (31761133017) and the Distinguished Young Scientists Fund of Fujian Agriculture and Forestry University of China (xjq202009).

Institutional Review Board Statement: Not applicable.

Informed Consent Statement: Not applicable.

Data Availability Statement: Sequence data can be found in The Arabidopsis Information Resource or GenBank/EMBL databases under the following numbers: TN2 (At1g17615), TN4 (At1g72850), TN5 (At1g72870), TN6 (At1g72890), TN7 (At1g72900), TN8 (At1g72910), TN9 (At1g72920), TN10 (At1g72930), TN11 (At1g72940), TN12 (At1g72950), TNL40 (At1g72840), TNL60 (At1g72860), RPS4 (At5g45250), L6 (AAA91021).

Acknowledgments: We thank Shuhua Yang for pSuper 1300-GFP and pSuper 1300-Myc vectors. We thank Gitta Coaker for Nicotiana tabacum seeds.

Conflicts of Interest: The authors declare no conflict of interest.

\section{References}

1. Teixeira, P.J.P.; Colaianni, N.R.; Fitzpatrick, C.R.; Dangl, J.L. Beyond pathogens: Microbiota interactions with the plant immune system. Curr. Opin. Microbiol. 2019, 49, 7-17. [CrossRef]

2. Jones, J.D.G.; Dangl, J.L. The plant immune system. Nature 2006, 444, 323-329. [CrossRef]

3. Dangl, J.L.; Horvath, D.M.; Staskawicz, B.J. Pivoting the plant immune system from dissection to deployment. Science 2013, 341, 746-751. [CrossRef]

4. Kourelis, J.; van der Hoorn, R.A.L. Defended to the nines: 25 years of resistance gene cloning identifies nine mechanisms for R protein function. Plant Cell 2018, 30, 285-299. [CrossRef]

5. Zhou, J.M.; Zhang, Y. Plant immunity: Danger perception and signaling. Cell 2020, 181, 978-989. [CrossRef] [PubMed]

6. Yu, X.; Feng, B.; He, P.; Shan, L. From chaos to harmony: Responses and signaling upon microbial pattern recognition. Annu. Rev. Phytopathol. 2017, 55, 109-137. [CrossRef] [PubMed]

7. Tang, D.; Wang, G.; Zhou, J.M. Receptor kinases in plant-pathogen interactions: More than pattern recognition. Plant Cell 2017, 29, 618-637. [CrossRef]

8. Zhang, R.; Zheng, F.; Wei, S.; Zhang, S.; Li, G.; Cao, P.; Zhao, S. Evolution of disease defense genes and their regulators in plants. Int. J. Mol. Sci. 2019, 20, 335. [CrossRef] [PubMed]

9. Gómez-Gómez, L.; Boller, T. FLS2: An LRR receptor-like kinase involved in the perception of the bacterial elicitor flagellin in Arabidopsis. Mol. Cell 2000, 5, 1003-1011. [CrossRef]

10. Bauer, Z.; Gómez-Gómez, L.; Boller, T.; Felix, G. Sensitivity of different ecotypes and mutants of Arabidopsis thaliana toward the bacterial elicitor flagellin correlates with the presence of receptor-binding sites. J. Biol. Chem. 2001, 276, 45669-45676. [CrossRef] [PubMed]

11. Kunze, G.; Zipfel, C.; Robatzek, S.; Niehaus, K.; Boller, T.; Felix, G. The N terminus of bacterial elongation factor Tu elicits innate immunity in Arabidopsis plants. Plant Cell 2004, 16, 3496-3507. [CrossRef] 
12. Zipfel, C.; Kunze, G.; Chinchilla, D.; Caniard, A.; Jones, J.D.G.; Boller, T.; Felix, G. Perception of the bacterial PAMP EF-Tu by the receptor EFR restricts Agrobacterium-mediated transformation. Cell 2006, 125, 749-760. [CrossRef] [PubMed]

13. Cabeen, M.T.; Losick, R. Bacterial backstabbing: EF-Tu, brute? Cell 2015, 163, 537-539. [CrossRef] [PubMed]

14. Wang, W.; Liu, N.; Gao, C.; Cai, H.; Romeis, T.; Tang, D. The Arabidopsis exocyst subunits EXO70B1 and EXO70B2 regulate FLS2 homeostasis at the plasma membrane. New Phytol. 2020, 227, 529-544. [CrossRef] [PubMed]

15. Monteiro, F.; Nishimura, M.T. Structural, functional, and genomic diversity of plant NLR proteins: An evolved resource for rational engineering of plant immunity. Annu. Rev. Phytopathol. 2018, 56, 243-267. [CrossRef]

16. Cesari, S. Multiple strategies for pathogen perception by plant immune receptors. New Phytol. 2018, 219, 17-24. [CrossRef]

17. Cui, H.; Tsuda, K.; Parker, J.E. Effector-triggered immunity: From pathogen perception to robust defense. Annu. Rev. Plant Biol. 2015, 66, 487-511. [CrossRef]

18. Wang, W.; Feng, B.; Zhou, J.M.; Tang, D. Plant immune signaling: Advancing on two frontiers. J. Integr. Plant Biol. 2020, 62, 2-24. [CrossRef]

19. Wang, J.; Hu, M.; Wang, J.; Qi, J.; Han, Z.; Wang, G.; Qi, Y.; Wang, H.W.; Zhou, J.M.; Chai, J. Reconstitution and structure of a plant NLR resistosome conferring immunity. Science 2019, 364, eaav5870. [CrossRef]

20. Maekawa, T.; Kufer, T.A.; Schulze-Lefert, P. NLR functions in plant and animal immune systems: So far and yet so close. Nat. Immunol. 2011, 12, 817-826. [CrossRef] [PubMed]

21. Li, X.; Kapos, P.; Zhang, Y. NLRs in plants. Curr. Opin. Immunol. 2015, 32, 114-121. [CrossRef] [PubMed]

22. Nandety, R.S.; Caplan, J.L.; Cavanaugh, K.; Perroud, B.; Wroblewski, T.; Michelmore, R.W.; Meyers, B.C. The role of TIR-NBS and TIR-X proteins in plant basal defense responses. Plant Physiol. 2013, 162, 1459-1472. [CrossRef] [PubMed]

23. Meyers, B.C.; Morgante, M.; Michelmore, R.W. TIR-X and TIR-NBS proteins: Two new families related to disease resistance TIR-NBS-LRR proteins encoded in Arabidopsis and other plant genomes. Plant J. 2002, 32, 77-92. [CrossRef]

24. Nasim, Z.; Fahim, M.; Gawarecka, K.; Susila, H.; Jin, S.; Youn, G.; Ahn, J.H. Role of AT1G72910, AT1G72940, and ADR1-LIKE 2 in plant immunity under nonsense-mediated mRNA decay-compromised conditions at low temperatures. Int. J. Mol. Sci. 2020, $21,7986$. [CrossRef]

25. Zhao, T.; Rui, L.; Li, J.; Nishimura, M.T.; Vogel, J.P.; Liu, N.; Liu, S.; Zhao, Y.; Dangl, J.L.; Tang, D. A truncated NLR protein, TIR-NBS2, is required for activated defense responses in the exo70B1 mutant. PLoS Genet. 2015, 11, e1004945. [CrossRef]

26. Wang, W.; Liu, N.; Gao, C.; Rui, L.; Tang, D. The Pseudomonas syringae effector AvrPtoB associates with and ubiquitinates Arabidopsis exocyst subunit EXO70B1. Front. Plant Sci. 2019, 10, 1027. [CrossRef] [PubMed]

27. Liu, N.; Hake, K.; Wang, W.; Zhao, T.; Romeis, T.; Tang, D. CALCIUM-DEPENDENT PROTEIN KINASE5 associates with the truncated NLR protein TIR-NBS2 to contribute to exo70B1-mediated immunity. Plant Cell 2017, 29, 746-759. [CrossRef] [PubMed]

28. Roth, C.; Lüdke, D.; Klenke, M.; Quathamer, A.; Valerius, O.; Braus, G.H.; Wiermer, M. The truncated NLR protein TIR-NBS13 is a MOS6/IMPORTIN- $\alpha 3$ interaction partner required for plant immunity. Plant J. 2017, 92, 808-821. [CrossRef] [PubMed]

29. Wang, Y.; Zhang, Y.; Wang, Z.; Zhang, X.; Yang, S. A missense mutation in CHS1, a TIR-NB protein, induces chilling sensitivity in Arabidopsis. Plant J. 2013, 75, 553-565. [CrossRef] [PubMed]

30. Zbierzak, A.M.; Porfirova, S.; Griebel, T.; Melzer, M.; Parker, J.E.; Dörmann, P. A TIR-NBS protein encoded by Arabidopsis Chilling Sensitive 1 (CHS1) limits chloroplast damage and cell death at low temperature. Plant J. 2013, 75, 539-552. [CrossRef]

31. Zhang, Y.; Wang, Y.; Liu, J.; Ding, Y.; Wang, S.; Zhang, X.; Liu, Y.; Yang, S. Temperature-dependent autoimmunity mediated by chs1 requires its neighboring TNL gene SOC3. New Phytol. 2017, 213, 1330-1345. [CrossRef]

32. Tong, M.; Kotur, T.; Liang, W.; Vogelmann, K.; Kleine, T.; Leister, D.; Brieske, C.; Yang, S.; Lüdke, D.; Wiermer, M.; et al. E3 ligase SAUL1 serves as a positive regulator of PAMP-triggered immunity and its homeostasis is monitored by immune receptor SOC3. New Phytol. 2017, 215, 1516-1532. [CrossRef] [PubMed]

33. Liang, W.; van Wersch, S.; Tong, M.; Li, X. TIR-NB-LRR immune receptor SOC3 pairs with truncated TIR-NB protein CHS1 or TN2 to monitor the homeostasis of E3 ligase SAUL1. New Phytol. 2019, 221, 2054-2066. [CrossRef] [PubMed]

34. Williams, S.J.; Sohn, K.H.; Wan, L.; Bernoux, M.; Sarris, P.F.; Segonzac, C.; Ve, T.; Ma, Y.; Saucet, S.B.; Ericsson, D.J.; et al. Structural basis for assembly and function of a heterodimeric plant immune receptor. Science 2014, 344, 299-303. [CrossRef] [PubMed]

35. Huh, S.U.; Cevik, V.; Ding, P.; Duxbury, Z.; Ma, Y.; Tomlinson, L.; Sarris, P.F.; Jones, J.D.G. Protein-protein interactions in the RPS4/RRS1 immune receptor complex. PLoS Pathog. 2017, 13, e1006376. [CrossRef] [PubMed]

36. Meyers, B.C.; Kozik, A.; Griego, A.; Kuang, H.; Michelmore, R.W. Genome-wide analysis of NBS-LRR-encoding genes in Arabidopsis. Plant Cell 2003, 15, 809-834. [CrossRef]

37. Xu, F.; Zhu, C.; Cevik, V.; Johnson, K.; Liu, Y.; Sohn, K.; Jones, J.D.; Holub, E.B.; Li, X. Autoimmunity conferred by chs3-2D relies on CSA1, its adjacent TNL-encoding neighbour. Sci. Rep. 2015, 5, 8792. [CrossRef]

38. Cesari, S.; Kanzaki, H.; Fujiwara, T.; Bernoux, M.; Chalvon, V.; Kawano, Y.; Shimamoto, K.; Dodds, P.; Terauchi, R.; Kroj, T. The NB-LRR proteins RGA4 and RGA5 interact functionally and physically to confer disease resistance. EMBO J. 2014, 33, 1941-1959. [CrossRef]

39. Zhai, C.; Zhang, Y.; Yao, N.; Lin, F.; Liu, Z.; Dong, Z.; Wang, L.; Pan, Q. Function and interaction of the coupled genes responsible for Pik-h encoded rice blast resistance. PLoS ONE 2014, 9, e98067. [CrossRef]

40. van Wersch, S.; Li, X. Stronger when together: Clustering of plant NLR disease resistance genes. Trends Plant Sci. 2019, 24, 688-699. [CrossRef] 
41. Wan, L.; Essuman, K.; Anderson, R.G.; Sasaki, Y.; Monteiro, F.; Chung, E.H.; Osborne Nishimura, E.; DiAntonio, A.; Milbrandt, J.; Dangl, J.L.; et al. TIR domains of plant immune receptors are NAD ${ }^{+}$-cleaving enzymes that promote cell death. Science 2019, 365, 799-803. [CrossRef]

42. Horsefield, S.; Burdett, H.; Zhang, X.; Manik, M.K.; Shi, Y.; Chen, J.; Qi, T.; Gilley, J.; Lai, J.S.; Rank, M.X.; et al. NAD ${ }^{+}$cleavage activity by animal and plant TIR domains in cell death pathways. Science 2019, 365, 793-799. [CrossRef]

43. Chang, M.; Clinton, M.; Liu, F.; Fu, Z.Q. NAD ${ }^{+}$cleavage: TIR domain-containing resistance proteins in action. Trends Plant Sci. 2019, 24, 1069-1072. [CrossRef] [PubMed]

44. van Ooijen, G.; Mayr, G.; Kasiem, M.M.A.; Albrecht, M.; Cornelissen, B.J.C.; Takken, F.L.W. Structure-function analysis of the NB-ARC domain of plant disease resistance proteins. J. Exp. Bot. 2008, 59, 1383-1397. [CrossRef] [PubMed]

45. Takken, F.L.W.; Albrecht, M.; Tameling, W.I. Resistance proteins: Molecular switches of plant defence. Curr. Opin. Plant Biol. 2006, 9, 383-390. [CrossRef] [PubMed]

46. Bonardi, V.; Cherkis, K.; Nishimura, M.T.; Dangl, J.L. A new eye on NLR proteins: Focused on clarity or diffused by complexity? Curr. Opin. Immunol. 2012, 24, 41-50. [CrossRef]

47. Howles, P.; Lawrence, G.; Finnegan, J.; McFadden, H.; Ayliffe, M.; Dodds, P.; Ellis, J. Autoactive alleles of the flax L6 rust resistance gene induce non-race-specific rust resistance associated with the hypersensitive response. Mol. Plant Microbe Interact. 2005, 18, 570-582. [CrossRef]

48. Yang, D.; Li, S.; Lu, L.; Fang, J.; Wang, W.; Cui, H.; Tang, D. Identification and application of the Pigm-1 gene in rice diseaseresistance breeding. Plant Biol. 2020, 22, 1022-1029. [CrossRef]

49. Liang, W.; Tong, M.; Li, X. SUSA2 is an F-box protein required for autoimmunity mediated by paired NLRs SOC3-CHS1 and SOC3-TN2. Nat. Commun. 2020, 11, 5190. [CrossRef]

50. Narusaka, M.; Iuchi, S.; Narusaka, Y. Analyses of natural variation indicates that the absence of RPS4/RRS1 and amino acid change in RPS4 cause loss of their functions and resistance to pathogens. Plant Signal. Behav. 2017, 12, e1293218. [CrossRef]

51. Deng, Y.; Zhai, K.; Xie, Z.; Yang, D.; Zhu, X.; Liu, J.; Wang, X.; Qin, P.; Yang, Y.; Zhang, G.; et al. Epigenetic regulation of antagonistic receptors confers rice blast resistance with yield balance. Science 2017, 355, 962-965. [CrossRef]

52. Heidrich, K.; Tsuda, K.; Blanvillain-Baufumé, S.; Wirthmueller, L.; Bautor, J.; Parker, J.E. Arabidopsis TNL-WRKY domain receptor RRS1 contributes to temperature-conditioned RPS4 auto-immunity. Front. Plant Sci. 2013, 4, 403. [CrossRef]

53. Ma, Y.; Guo, H.; Hu, L.; Martinez, P.P.; Moschou, P.N.; Cevik, V.; Ding, P.; Duxbury, Z.; Sarris, P.F.; Jones, J.D.G. Distinct modes of derepression of an Arabidopsis immune receptor complex by two different bacterial effectors. Proc. Natl. Acad. Sci. USA 2018, 115, 10218-10227. [CrossRef]

54. Nishimura, M.T.; Anderson, R.G.; Cherkis, K.A.; Law, T.F.; Liu, Q.L.; Machius, M.; Nimchuk, Z.L.; Yang, L.; Chung, E.H.; El Kasmi, F.; et al. TIR-only protein RBA1 recognizes a pathogen effector to regulate cell death in Arabidopsis. Proc. Natl. Acad. Sci. USA 2017, 114, E2053-E2062. [CrossRef]

55. Feng, B.; Tang, D. Mechanism of plant immune activation and signaling: Insight from the first solved plant resistosome structure. J. Integr. Plant Biol. 2019, 61, 902-907. [CrossRef]

56. Ma, S.; Lapin, D.; Liu, L.; Sun, Y.; Song, W.; Zhang, X.; Logemann, E.; Yu, D.; Wang, J.; Jirschitzka, J.; et al. Direct pathogen-induced assembly of an NLR immune receptor complex to form a holoenzyme. Science 2020, 370, eabe3069. [CrossRef] [PubMed]

57. Martin, R.; Qi, T.; Zhang, H.; Liu, F.; King, M.; Toth, C.; Nogales, E.; Staskawicz, B.J. Structure of the activated ROQ1 resistosome directly recognizing the pathogen effector XopQ. Science 2020, 370, eabd9993. [CrossRef] [PubMed]

58. Zhao, Y.; Wu, G.; Shi, H.; Tang, D. RECEPTOR-LIKE KINASE 902 associates with and phosphorylates BRASSINOSTEROIDSIGNALING KINASE1 to regulate plant immunity. Mol. Plant 2019, 12, 59-70. [CrossRef] [PubMed]

59. Gao, C.; Sun, P.; Wang, W.; Tang, D. Arabidopsis E3 ligase KEG associates with and ubiquitinates MKK4 and MKK5 to regulate plant immunity. J. Integr. Plant Biol. 2021, 63, 327-339. [CrossRef] [PubMed]

60. Chen, H.; Zou, Y.; Shang, Y.; Lin, H.; Wang, Y.; Cai, R.; Tang, X.; Zhou, J.M. Firefly luciferase complementation imaging assay for protein-protein interactions in plants. Plant Physiol. 2008, 146, 368-376. [CrossRef]

61. Yoo, S.D.; Cho, Y.H.; Sheen, J. Arabidopsis mesophyll protoplasts: A versatile cell system for transient gene expression analysis. Nat. Protoc. 2007, 2, 1565-1572. [CrossRef] [PubMed] 